\title{
STRYCHNINE BLOCKS BINAURAL INHIBITION IN LATERAL SUPERIOR OLIVARY NEURONS ${ }^{1}$
}

\author{
MAURUS J. MOORE AND DONALD M. CASPARY ${ }^{2}$
}

Department of Pharmacology, Southern Illinois University, School of Medicine, Springfield, Illinois

Received May 13, 1982; Revised July 26, 1982; Accepted August 13, 1982

\begin{abstract}
The present study seeks to identify neurotransmitters mediating binaural inhibition in lateral superior olivary nucleus neurons. Neurons in this auditory structure receive inputs from both ears and are thought to code for localization of sound in space. Iontophoretic application of glycine during monaural stimulation was found to mimic the inhibition observed with binaural stimulation. Binaural inhibition was blocked by application of the glycine receptor antagonist, strychnine, as were the effects of iontophoretic application of glycine. The post-strychnine recovery time course for return of synaptically mediated binaural inhibition and recovery of the effects of iontophoretic glycine application were identical. Although the superior olivary complex (SOC) neurons displaying binaural inhibition could in some cases be inhibited by GABA, the binaural inhibition rarely was blocked by iontophoretic application of the GABA receptor antagonist, bicuculline. These findings suggest that glycine may be a neurotransmitter mediating binaural inhibition in certain SOC neurons and that the projection to the lateral superior olivary nucleus from the medial nucleus of the trapezoid body may be glycinergic.
\end{abstract}

The superior olivary complex (SOC) is the first structure in the ascending auditory pathway to receive bilateral input (for review see Boudreau and Tsuchitani, 1970; Brugge and Geisler, 1978; Tsuchitani, 1978). The auditory nerve on each side projects from the cochlea to the cochlear nucleus on that side. Binaural neurons in the lateral superior olive (LSO) receive their predominant contralateral input from the opposite ventral cochlear nucleus (VCN) via a secure synapse in the ipsilateral medial nucleus of the trapezoid body (MNTB; see Fig. 1). Ipsilateral input comes directly from the homolateral VCN to the same neuron. Ultrastructural studies indicate the existence of at least three types of synaptic endings upon the neurons of the medial superior olive (MSO). The morphological characteristics of these endings suggest that some may be inhibitory but others may be excitatory (Clark, 1969; Perkins, 1973; Schwartz, 1980). Although comparable morphological evidence has not been reported for the lateral superior olive (LSO), elec-

\footnotetext{
'We thank D. C. Havey for excellent technical assistance, John Baumgartner and the Department of Biomedical Illustration for help with preparation of the figures, and Tammy Kissel for typing the manuscript. We also thank Drs. Albert Feng, George Moushegian, Carl Faingold, and Leonard Rybuk for critical comments. The research was supported by National Institutes of Health Grant NS15640, the Pearson Family Foundation, and Southern Illinois University School of Medicine-Central Research Committee funds.

${ }^{2}$ To whom correspondence should be addressed at Department of Pharmacology, Southern Illinois University, School of Medicine, P. O. Box 3926, Springfield, IL 62708.
}

trophysiological evidence indicates the existence of neurons in both the MSO and LSO which are excited by inputs from one ear and inhibited by simultaneous stimulation of the opposite ear (Galambos et al., 1959; Goldberg and Brown, 1968, 1969; Guinan et al., 1972a, b; Tsuchitani, 1977, 1978).

The nature of the neurotransmitter mechanisms mediating this inhibition is not known, but the existence of binaural neurons within the SOC provides an opportunity to study the interaction between excitatory and inhibitory synaptic inputs by varying the acoustic stimulus to each ear. Recently, Zarbin et al. (1981), using autoradiographic evidence, demonstrated that strychnine, the specific glycine antagonist, displays significant receptor binding in the rat LSO and minimal binding in the rat MSO.

The present study examines binaural inhibition and attempts to antagonize the synaptically mediated binaural inhibition by iontophoretic application of the inhibitory amino acid antagonists, strychnine or bicuculline. The actions of exogenously applied glycine and GABA then are compared to the inhibition produced by the endogenous synaptically released inhibitory neurotransmitter.

\section{Materials and Methods}

Chinchilla, Chinchilla laniger, weighing 300 to $600 \mathrm{gm}$ were anesthetized initially with sodium pentobarbital (40 $\mathrm{mg} / \mathrm{kg}$ ), followed $30 \mathrm{~min}$ later by ketamine hydrochloride 


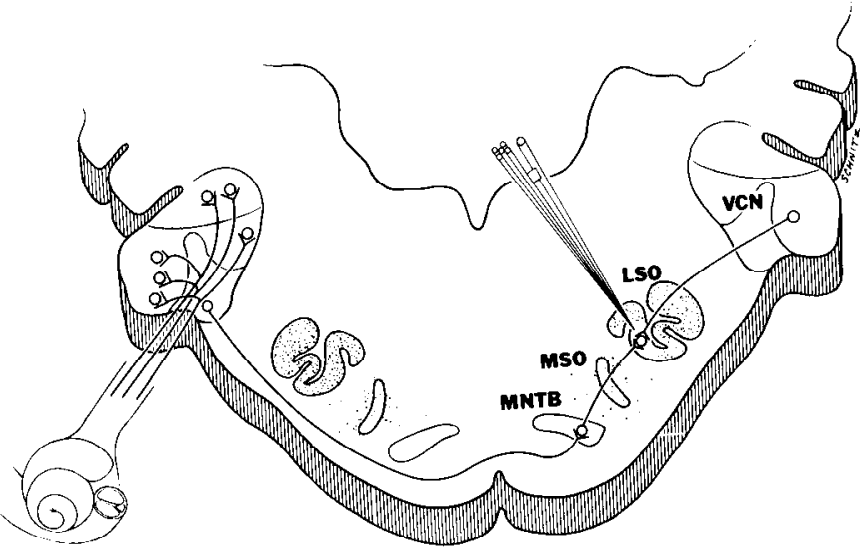

Figure 1. A schematic representation of the innervation of binaural neurons in the lateral superior olive $(L S O)$. Ipsilateral input to these neurons derives from the anterior regions of the ventral cochlear nucleus ( $V C N$ ). Contralateral input from the interstitial nucleus of the opposite VCN traverses the midline to synapse in the medial nucleus of the trapezoid body $(M N T B)$, which in turn projects to the LSO. The present study finds that strychnine blocks binaural inhibition in neurons of the LSO which receive a prominent input from the MNTB.

$(40 \mathrm{mg} / \mathrm{kg})$. Supplementary injections of sodium pentobarbital were given as needed to maintain anesthesia. Because of the effect of pentobarbital on neuronal response patterns (Young and Brownell, 1976) and on amino acid neurotransmitter release (Potashner and Lake, 1981), some animals were anesthetized with and maintained on ketamine alone. The animal was placed in a sound-attenuating chamber (Industrial Acoustics Co., Inc.) and body temperature was monitored and maintained by a thermostatically controlled DC heating pad.

A posterior fossa approach was used to allow alignment of the electrode parallel to the major axis of the MSO. This permitted independent punctures of the three main nuclei comprising the SOC in chinchillas. Details of the surgical procedures have been described previously (Caspary, 1972; Caspary et al., 1979) with the following additions. Extracellular recordings were obtained with a glass micropipette (tip diameter, 1.0 to $1.5 \mu \mathrm{m}$ ) glued alongside a five-barrel micropipette (Glass Co. of America) (outer tip diameter, 8 to $10 \mu \mathrm{m}$ ) so that the single barrel tip protruded 3 to $7 \mu \mathrm{m}$ beyond the tip of the five-barrel electrode. A balancing or summating channel was employed to alleviate current effects, and this barrel and the recording micropipette were filled with $2.0 \mathrm{M}$ potassium acetate. In some experiments the recording barrel was filled with Alcian blue $(8 \%$ in $0.5 \mathrm{~m}$ sodium acetate (Lee et al., 1969)) to allow for marking of individual recording locations. The remaining four barrels contained $0.5 \mathrm{M}$ glycine, $\mathrm{pH} 3.5$ to 4.0 (Sigma Chemical Co.); $0.002 \mathrm{M}$ strychnine (Sigma); 0.5 M GABA, pH 3.5 to 4.0 (Sigma); and $0.001 \mathrm{M}$ bicuculline (Sigma). In some experiments 0.5 M picrotoxin (Sigma) was substituted for bicuculline. Ejection, retention, and balancing currents were produced by a constant current source (Medical Systems, Inc. model BH-2).

Upon termination of the experiment, the animal was sacrificed with sodium pentobarbital and underwent cardiac perfusion with saline followed by $10 \%$ formalin. The relevant portion of the brain was serially sectioned in the plane of the electrode and tracings were made of all sections containing electrode tracks to enable reconstruction of penetrations through the SOC.

Fifty coherent tone bursts ( 50 or 100 msec duration, 5 or $10 \mathrm{msec}$ rise/fall) were presented at the rate of $2 / \mathrm{sec}$. Auditory stimuli were delivered through TDH-49 earphones (Telephonics) and calibrated at the level of the external auditory meatus using a Bruel and Kjaer 0.25inch condenser microphone. The system was calibrated from 0.05 to $30.0 \mathrm{kHz}$ and attenuation data were corrected to $\mathrm{dB}$ SPL re $0.0002 \mathrm{dyne} / \mathrm{cm}^{2}$. No binaural intensity differences of greater than $20 \mathrm{~dB}$ sound pressure level (SPL) were used in the present study, and all decibel values are in SPL.

Neuronal responses were processed on-line with a PDP-8E computer (Digital Equipment Corp.) and were stored simultaneously on analog magnetic tape (Tandberg 100) for subsequent off-line processing. Rapid onset noise bursts ( $3 \mathrm{msec}$ duration, $20 \mathrm{msec}$ interaural delay) were used as search stimuli. Both excitatory and inhibitory response areas and best frequency were obtained for all neurons encountered. Poststimulus time histograms (PSTHs), interspike interval histograms (ISIHs), and spike counts were obtained for all neurons before, during, and subsequent to the iontophoretic administration of the putative amino acid transmitters and their antagonists.

The experimental paradigm used varied somewhat depending upon the response characteristics of the neuron being studied. To classify neurons, the following PSTHs were obtained: $(a)$ monaural contralateral, $(b)$ binaural, and $(c)$ monaural ipsilateral. When binaural stimulation revealed inhibition, intensities and phase were varicd to maximize the inhibitory effect. The following iontophoretic paradigm then was implemented: ( $a$ ) GABA or glycine was applied during monaural stimulation in an effort to mimic the endogenous binaural inhibition; $(b)$ strychnine, bicuculline, or, in some cases, picrotoxin was applied continuously during binaural stimulation in order to block the synaptically mediated inhibition; and (c) GABA or glycine was introduced during or immediately following application of its respective antagonist.

\section{Results}

One hundred and nineteen neurons were tested with iontophoretic application of GABA, glycine, strychnine, and bicuculline or picrotoxin and were located in or immediately surrounding the LSO. Only neurons from punctures that penetrated a major portion of the LSO are included, while data from punctures which penetrated the MNTB or MSO are not included in the present study. Thirteen neurons responded to monaural stimulation alone, either ipsilaterally or contralaterally, while 106 neurons responded to binaural stimulation. Seventynine of the binaural neurons were inhibited during binaural stimulation, while 27 were not. Of neurons showing binaural inhibition, $81 \%$ could be inhibited by glycine during monaural stimulation, which mimicked the binaural condition (synaptic inhibition) (Table I). Iontophoretic application of strychnine resulted in blocking of endogenous inhibition in $82 \%$ of these neurons while blocking the effects of subsequent simultaneous iontophoretic application of glycine in $97 \%$ of the neurons 
TABLE I

Effects of iontophoresis on binaurally inhibited LSO neurons

\begin{tabular}{llcc}
\hline \multicolumn{1}{c}{ Substance } & $\begin{array}{c}\text { Stimulus } \\
\text { Condition }\end{array}$ & $\begin{array}{c}\text { Number of } \\
\text { Neurons } \\
\text { Tested }\end{array}$ & $\begin{array}{c}\text { Percentage } \\
\text { of Neurons } \\
\text { Affected }\end{array}$ \\
\hline Glycine & Monaural & 68 & 81 \\
Strychnine & Binaural & 54 & 82 \\
Strychnine and glycine & Monaural & 33 & 97 \\
GABA & Monaural & 67 & 72 \\
Bicuculline & Binaural & 15 & 7 \\
Bicuculline and GABA & Monaural & 50 & 50 \\
\hline
\end{tabular}

examined (Table I). GABA was also effective in mimicking binaural inhibition (72\%), but only $7 \%$ of the neurons tested showed blocking of the synaptically mediated binaural inhibition with the application of the GABA antagonist, bicuculline (Table I). A $\chi^{2}$ test of the difference between the effects of bicuculline and strychnine on binaural inhibition was highly significant $\left(\chi^{2}=25.76\right.$; $d f$ $=1 ; p<0.001$ ). Bicuculline was effective only $50 \%$ of the time in blocking the effects of iontophoretically applied GABA (Table I).

An example of a neuron that exhibited a phasic response and was typical of the largest population of LSO neurons is seen in Figure 2. Ipsilateral stimulation (right ear) (Fig. 2A) results in an "on-type" response, while binaural stimulation results in complete inhibition of the ipsilateral response (Fig. $2 B$ ). Glycine application during ipsilateral stimulation (Fig. $2 C$ ) greatly reduces the response, thus mimicking the binaural condition. Figure $2 E$ displays the blocking of the endogenous synaptic inhibition by strychnine which is seen to return the response to a pattern similar to the ipsilateral (monaural right) stimulation. Glycine inhibition is blocked by strychnine (Fig. $2 F$ ) and GABA application has little effect (Fig. $2 L$ ). The neuron displayed in Figure 2 and another extensively studied neuron (R47-3, Figs. 3 and 4) are representative of the consistent blocking of binaural inhibition produced by iontophoretic application of strychnine. The neuron in Figure 3 also is driven by ipsilateral stimulation and is inhibited binaurally (Fig. 3, $A$ and $B$ ). Glycine application (Fig. $3 C$ ) mimics the binaural condition and the effect is blocked by strychnine (Fig. $3 F$ ). Figure $3 E$ shows that strychnine blocks much of the binaural inhibition (compare with Fig. $3 B$ ).

Recovery from strychnine was monitored by a series of binaural histograms and monaural histograms accompanied by glycine application. The return of glycine effectiveness coincided with the reappearance of a control level of binaural inhibition. The recovery time from strychnine application varied between 5 and $25 \mathrm{~min}$. Rate intensity curves for the neuron seen in Figure 3 are displayed in Figure 4. Binaural inhibition develops at intensities greater than $14 \mathrm{~dB}$ (Fig. $4 B$ ) and is mimicked in the monaural plus glycine condition (Fig. $4 C$ ). Iontophoretic application of strychnine at each intensity (Fig. $4 D$ ) results in a curve similar to that of the monaural control (Fig. $4 A$ ) except for a slight increase in overall response. Differences seen between curves $B$ and $D$ in Figure 4 are representative of findings for other neurons for which data at multiple intensities were obtained.

An example of a neuron displaying excitation with monaural stimulation, ipsilateral or contralateral, and inhibition with binaural stimulation is displayed in Figure 5. The ipsilateral stimulation plus glycine (Fig. $5 D$ ) mimics the binaural condition (Fig. $5 B$ ). Strychnine reverses the synaptically mediated binaural inhibition (Fig. $5 E$ ) and blocks the effects of simultaneously applied glycine (Fig. $5 F$ ) during binaural stimulation.

Among purely excitatory binaural neurons, GABA appeared to be somewhat more effective $(80 \% ; 16$ of 20 neurons) than glycine $(69.6 \%$; 16 of 23 neurons) in producing inhibition, but the difference was not statistically significant.

Certain low frequency neurons exhibit binaural inhibition only when there is a fixed temporal relationship between the two ears. This temporal difference corresponds to a fixed phase relationship at any given frequency when a given frequency is delivered binaurally. Fourteen of these neurons were tested iontophoretically. Seven of 10 neurons showed blocking of the phase-dependent, synaptically mediated binaural inhibition with

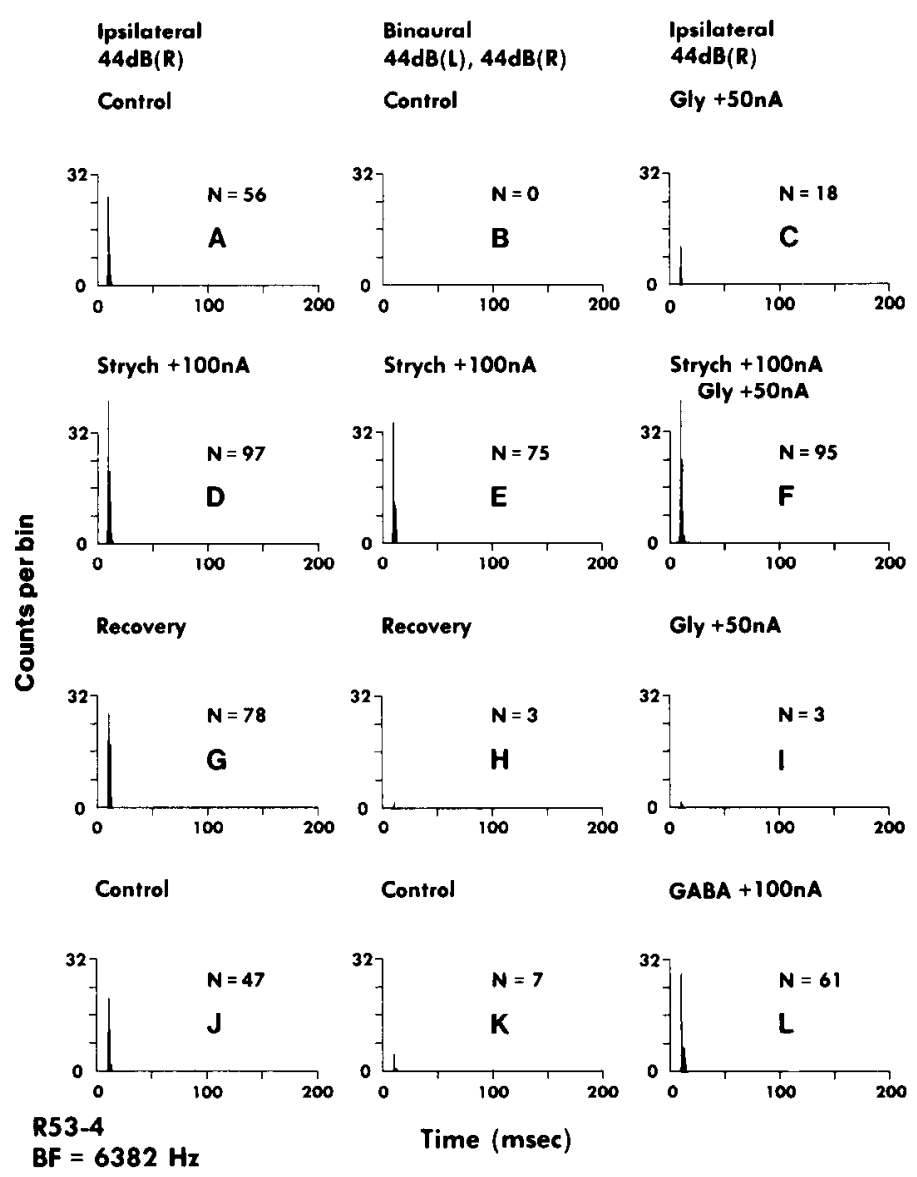

Figure 2. PSTHs of neuronal activity to $100-\mathrm{msec}$ tone burst stimuli showing the effects of iontophoretically applied glycine $(G l y)$, strychnine (Strych), and GABA on a phasic responder from the lateral superior olive ( $L S O)$. The left and right columns display the response to ipsilateral stimuli at $44 \mathrm{~dB}$ SPL, while the response to binaural stimuli at $44 \mathrm{~dB}$ SPL is seen in the center column. This neuron was excited by an ipsilateral stimulus $(A)$ and was inhibited by binaural stimuli $(B)$. Glycine application reduces the ipsilateral response $(C)$ or mimicry of the binaural condition. Strychnine application blocks binaural inhibition $(E)$ and glycine inhibition $(F)$. Note that GABA application has little effect $(L) . B F$, best frequency. 


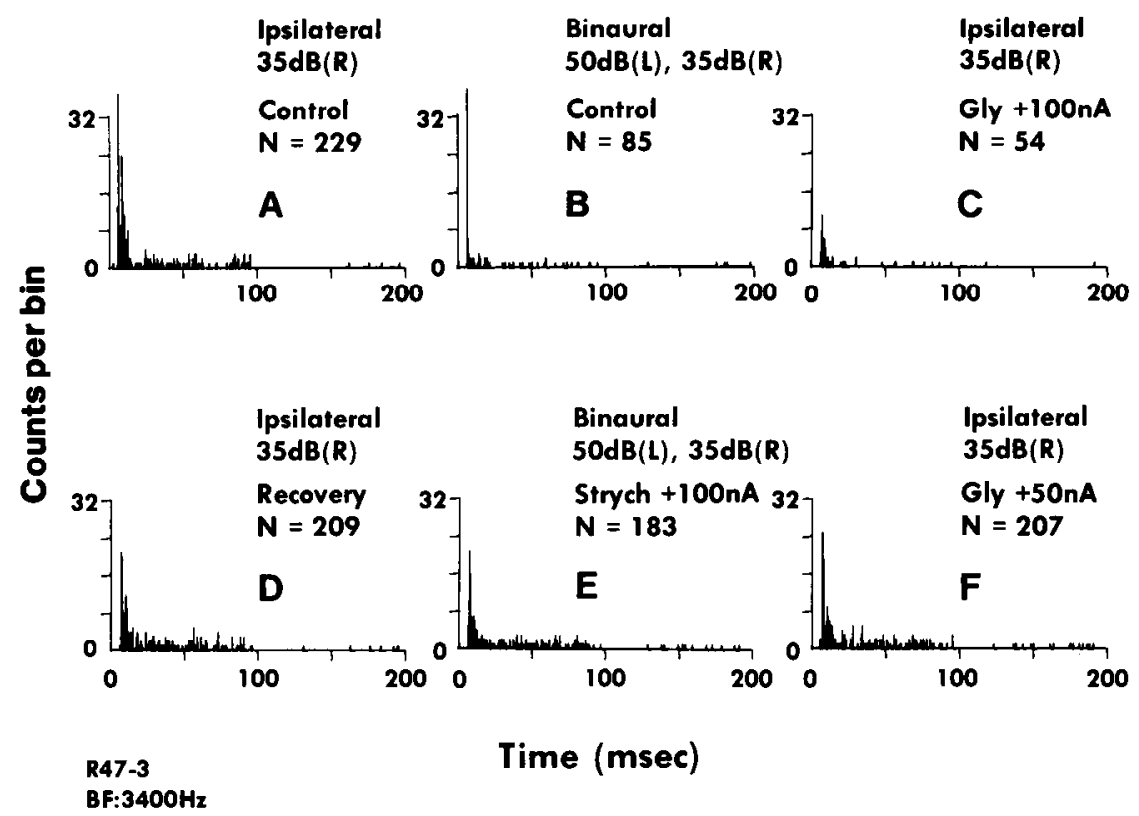

Figure 3. PSTHs of activity of an LSO neuron for $100-\mathrm{msec}$ tone presentations. This neuron was driven by ipsilateral stimulation $(A)$ and was inhibited binaurally $(B)$. Glycine application mimics the binaural response $(C)$. Strychnine antagonizes binaural inhibition. The residual level of strychnine is sufficient to block the effect of iontophoretic application of glycine $(F)$. $B F$, best frequency.

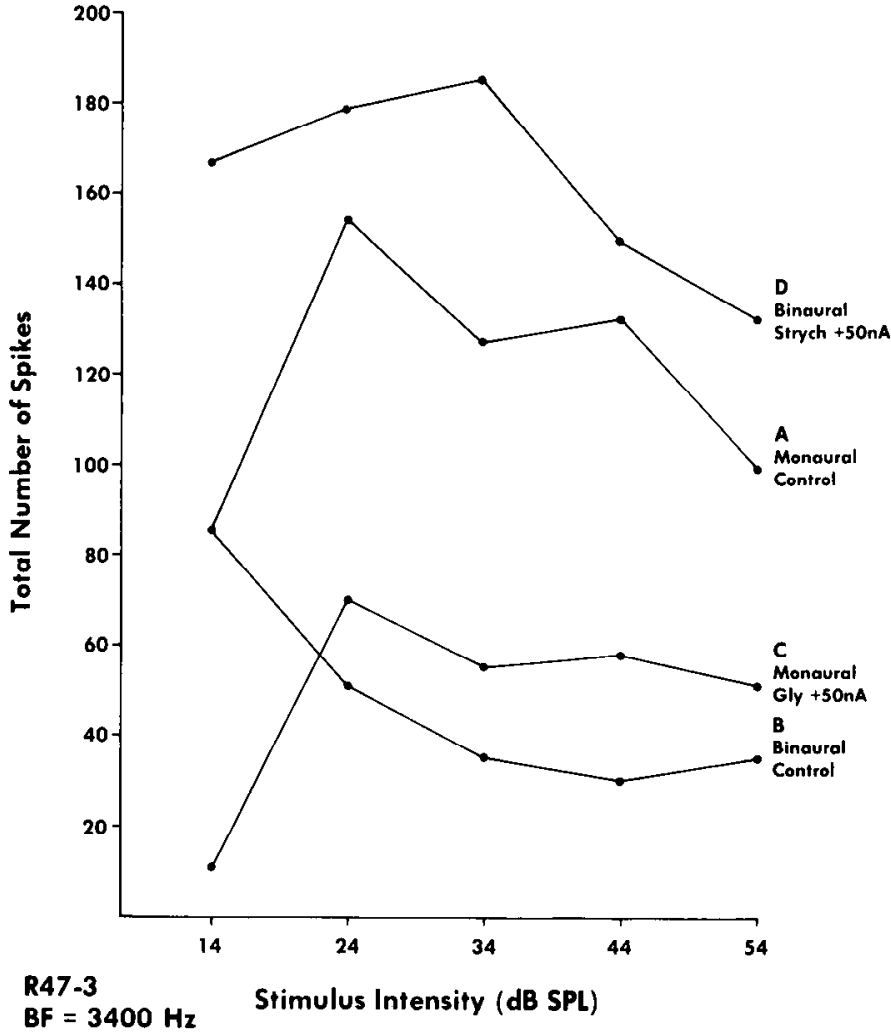

Figure 4. Response rates for each of the experimental conditions as a function of stimulus intensity. Intensities at both ears were set to the same level for the binaural condition. Strychnine $(D)$ blocks the inhibition produced by binaural stimulation $(B)$. Strychnine also raises the overall activity beyond the monaural control level $(A)$. Glycine reduces the level of response $(C)$ without alteration of the profile across stimulus intensity. iontophoretic strychnine. A $180^{\circ}$ out-of-phase binaural stimulus inhibits the monaural response (Fig. 6, $A$ and $B$ ) of this neuron located in the lateral lobe of the LSO. The in-phase condition (not shown) has no effect, while the application of glycine during monaural stimulation (Fig. 6C) mimics the out-of-phase condition. Strychnine blocks both the effect of iontophoretic application of glycine and the synaptically released transmitter evoked by binaural out-of-phase stimuli (Fig. $6, D$ and $E$ ). The binaural inhibition returns (Fig. $6 F$ ) simultaneously with the return of the effect of iontophoretic glycine application. None of the phase-sensitive neurons tested displayed reversal of inhibition with bicuculline. Ninety-five percent of these neurons (12 of 14) were inhibited by glycine, while only $48 \%$ ( 6 of 13 ) were inhibited by GABA.

\section{Discussion}

Neurons located in the LSO receive inputs from both ears and are thought to act as comparators to produce an output coded for spatial localization of sound (for review see Erulkar, 1972; Brugge and Geisler, 1978; Tsuchitani, 1978). The inputs to the LSO nucleus are from the ipsilateral spherical cell area of the anteroventral cochlear nucleus with the contralateral input originating from ipsilateral MNTB neurons which receive input from the globular cell in the contralateral interstitial nucleus and the anterior portion of the posterior ventral cochlear nucleus (Rasmussen, 1967; Harrison and Feldman, 1970; Browner and Webster, 1975). The ultrastructural studies of the afferent terminals in the SOC of the cat (Clark, 1969; Lindsey, 1975; Schwartz, 1980) and chinchilla (Perkins, 1973) indicate the presence of type I, II, and III endings, suggesting that both excitatory and inhibitory endings are present (Uchizono, 1975). Although this is best documented in the MSO, a similar 
Ipsilateral

$30 \mathrm{~dB}(\mathrm{R})$

Control

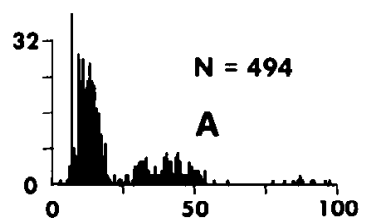

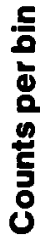

Ipsilateral

$30 \mathrm{~dB}(R)$

Gly +150nA

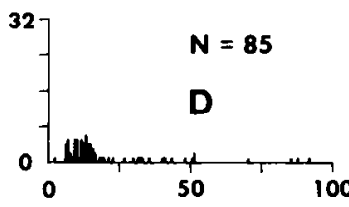

R33-3

$B F=3900 \mathrm{~Hz}:(\mathrm{L})$

$B F=4700 \mathrm{~Hz}:(R)$
Binaural

$30 \mathrm{~dB}(L), 30 \mathrm{~dB}(\mathrm{R})$

Control

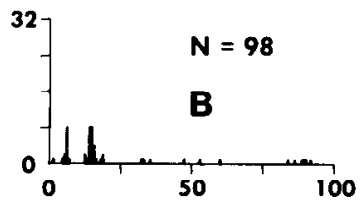

Binaural

$30 \mathrm{~dB}(\mathrm{~L}), 30 \mathrm{~dB}(\mathrm{R})$

Strych +150nA

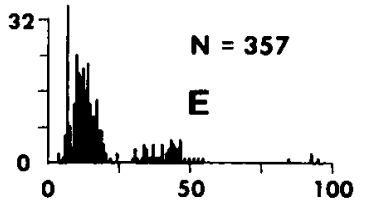

Time (msec)
Contralateral

$30 \mathrm{~dB}(\mathrm{~L})$

Control

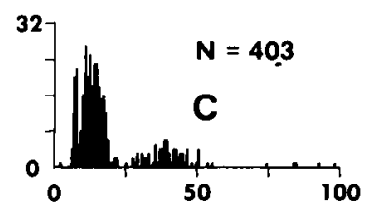

\section{Binaural}

$30 \mathrm{~dB}(\mathrm{~L}), 30 \mathrm{~dB}(\mathrm{R})$

Gly +150nA

Strych +150nA

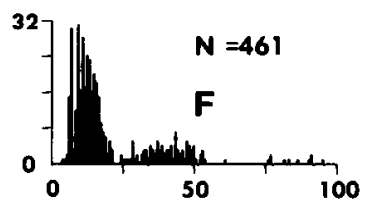

Figure 5. PSTHs (50-msec stimulus duration) of a neuron displaying excitation with monaural stimulation, ipsilateral (A) or contralateral $(C)$, and inhibition with binaural stimulation $(B)$ at $30 \mathrm{~dB}$ SPL. Glycine application during ipsilateral stimulation $(D)$ mimics the binaural response. Subsequent application of strychnine blocked both binaural inhibition $(E)$ and the combined effect of glycine application and binaural stimulation $(F)$.

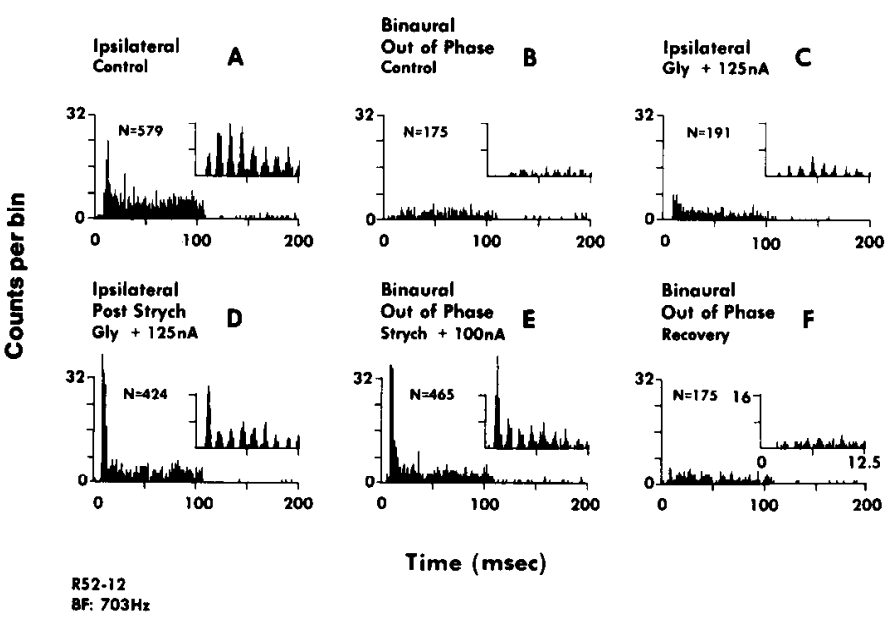

Figure 6. PSTHs showing the responses of a neuron located in the lateral lobe of the LSO (100-msec stimulus duration). Interspike interval histograms with the ordinate as 32 intervals are seen in the upper right corner of the PSTHs. The monaural response $(A)$ is inhibited by the binaural $180^{\circ}$ out-of-phase stimulus $(B)$. Glycine inhibits the response before strychnine application $(C)$ which subsequently blocks the glycine inhibition $(F)$ and the synaptic inhibition seen in the binaural condition $(E)$.

arrangement of synaptic inputs is thought to be present in the LSO (I. R. Schwartz, personal communication). Evidence supporting the presence of excitatory and inhibitory endings impinging on LSO neurons is provided by electrophysiological studies (Galambos et al., 1959; Boudreau and Tsuchitani, 1970; Guinan et al., 1972a, b; Tsuchitani, 1977) which indicate that many of these neurons show inhibition with binaural stimulation. Two previous studies describe $86 \%$ (222 of 259 ) of binaurally inhibited-ipsilaterally excited (IE) neurons were located in the LSO (Guinan et al., 1972a, b; Tsuchitani, 1977). The present study also found the IE response type to be the prevalent pattern located within the LSO. The localization of tracks to the LSO in the present study was simplified by the long passage through the medulla and the orientation parallel to the axis of the MSO in parahorizontal section. Only neurons from punctures that passed through a major portion of the LSO were included in the present study. The two detailed structure-function studies of the cat SOC (Guinan et al., 1972a, b; Tsuchitani, 1977) indicate that the two most proximate structures, the lateral trapezoid nucleus and the dorsolateral periolivary nucleus, show binaural inhibition in only $18 \%$ of the neurons studied.

The precision with which excitation and inhibition may be controlled by manipulating the acoustic input to SOC neurons provides an excellent substrate for the study of excitatory and inhibitory interactions. The present study finds that contralateral inhibition can be blocked with strychnine and mimicked by iontophoretic application of glycine. Light microscopic autoradiographic studies (Zarbin et al., 1981) show binding of $\left[{ }^{3} \mathrm{H}\right]$ strychnine in the LSO but not in the MSO. In addition, there appears to be a lateral to medial increase 
in the number of binding sites found in the LSO (M. A. Zarbin, personal communication). Although the locus of action has not been defined, alterations of auditory sensation have also been reported by humans suffering from strychnine toxicity (Gosselin et al., 1976) or following the administration of subconvulsant doses (Clark, 1938). The inability of bicuculline to block GABA inhibition could be due to the presence of bicuculline-insensitive GABA receptors (Bowery et al., 1981). It is also possible that after several hours within the brain, bicuculline at the electrode tip could be degraded by mixing with cerebrospinal fluid, causing an increased $\mathrm{pH}$ and loss of stability (Olsen et al., 1975).

The presence of strychnine binding in the LSO and our findings that strychnine can block synaptically mediated binaural inhibition and that glycine can mimic synaptically mediated inhibition suggest that glycine may be a neurotransmitter mediating contralateral inhibition in the LSO (Fig. 1). Since the source of this inhibition is thought to be the fibers projecting from the medial nucleus of the trapezoid body onto neurons of the LSO of the same side, this suggests that the projection pathway utilizes glycine as a neurotransmitter.

\section{References}

Boudreau, J. C., and C. Tsuchitani (1970) Cat superior olive Ssegment cell discharge to tonal stimulation. In Contributions to Sensory Physiology, W. D. Neff, ed., Vol. 4, pp. 143-213, Academic Press, Inc., New York.

Bowery, N. G., A. Doble, D. R. Hill, A. L. Hudson, M. J. Turnbull, and R. Warrington (1981) Structure/activity studies at a baclofen-sensitive, bicuculline-insensitive GABA receptor. In Amino Acid Neurotransmitters, F. V. DeFeudis and P. Mandel, eds., pp. 333-341, Raven Press, New York.

Browner, R. H., and D. B. Webster (1975) Projections of the trapezoid body and the superior olivary complex of the kangaroo rat (Dipodomys merriami). Brain Behav. Evol. 11: 322-354.

Brugge, J. F., and C. D. Geisler (1978) Auditory mechanisms of the lower brainstem. Annu. Rev. Neurosci. 1: 63-94.

Caspary, D. M. (1972) Classification of subpopulations of neurons in the cochlear nuclei of the kangaroo rat. Exp. Neurol. 37: 131-151.

Caspary, D. M., D. C. Havey, and C. L. Faingold (1979) Effects of microiontophoretically applied glycine and GABA on neuronal response patterns in the cochlear nuclei. Brain Res. 172: $179-185$.

Clark, A. J. (1938) Applied Pharmacology, Ed. 6, pp. 255-259, P. Blakiston's Son and Co., Inc., Philadelphia.

Clark, G. M. (1969) The ultrastructure of nerve endings in the medial superior olive of the cat. Brain Res. 14: 293-305.

Erulkar, S. D. (1972) Comparative aspects of spatial localization of sound. Physiol. Rev. 52: 237-360.

Galambos, R., J. Schwartzkopff, and A. Rupert (1959) Microelectrode study of superior olivary nuclei. Am. J. Physiol. 197: 527-536.

Goldberg, J. M., and P. B. Brown (1968) Functional organiza- tion of the dog superior olivary complex: An anatomical and electrophysiological study. J. Neurophysiol. 31: 639-656.

Goldberg, J. M., and P. B. Brown (1969) Response of binaural neurons of dog superior olivary complex to dichotic tonal stimuli: Some physiological mechanisms of sound localization. J. Neurophysiol. 32: 613-636.

Gosselin, R. E., H. C. Hodge, R. P. Smith, and M. N. Gleason (1976) Strychnine. In Clinical Toxicology of Commercial Products, Ed. 4, pp. 303-307, The Williams and Wilkins Co., Baltimore.

Guinan, J. J., S. S. Guinan, and B. E. Norris (1972a) Single auditory units in the superior olivary complex. I. Responses to sounds and classifications based on physiological properties. Int. J. Neurosci. 4: 101-120.

Guinan, J. J., B. E. Norris, and S. S. Guinan (1972b) Single auditory units in the superior olivary complex. II. Locations of unit categories and tonotopic organization. Int. J. Neurosci. 4: $147-166$.

Harrison, J. M., and M. L. Feldman (1970) Anatomical aspects of the cochlear nucleus and superior olivary complex. In Contributions to Sensory Physiology, W. D. Neff, ed., Vol. 4, pp. 95-143, Academic Press, Inc., New York.

Lee, B. B., G. Mandl, and J. P. B. Stean (1969) Microelectrode tip position marking in nervous tissue: A new dye method. Electroencephalogr. Clin. Neurophysiol. 27: 610-613.

Lindsey, B. G. (1975) Fine structure and distribution of axon terminals from the cochlear nucleus on neurons in the medial superior olivary nucleus of the cat. J. Comp. Neurol. 160: 81104.

Olsen, R. W., M. Ban, T. Miller, and G. A. R. Johnston (1975) Chemical instability of the GABA antagonist bicuculline under physiological conditions. Brain Res. 98: 383-387.

Perkins, R. E. (1973) An electron microscopic study of synaptic organization in the medial superior olive of normal and experimental chinchillas. J. Comp. Neurol. 148: 387-416.

Potashner, S. J., and N. Lake (1981) Action of baclofen and pentobarbital on amino acid release. In Glutamate as a Neurotransmitter, G. Di Chiara and G. L. Gessa, eds., pp. 139-145, Raven Press, New York.

Rasmussen, G. L. (1967) Efferent connections of the cochlear nucleus. In Sensorineural Hearing Processes and Disorders, A. B. Graham, ed., pp. 61-75, Little, Brown and Co., Boston.

Schwartz, I. R. (1980) The differential distribution of synaptic terminal on marginal and central cells in the cat medial superior olivary nucleus. Am. J. Anat. 159: 25-31.

Tsuchitani, C. (1977) Functional organization of lateral cell groups of cat superior olivary complex. J. Neurophysiol. 40: 296-317.

Tsuchitani, C. (1978) Lower auditory brainstem structures of the cat. In Evoked Electrical Activity in the Auditory Nerv. ous System, R. F. Naunton and C. Fernandez, eds., pp. 373401, Academic Press, Inc., New York.

Uchizono, K. (1975) Excitation and Inhibition: Synaptic morphology. Elsevier Scientific Publishing Co., New York.

Young, E. D., and W. E. Brownell (1976) Responses to tones and noise of single cells in dorsal cochlear nucleus of unanesthetized cats. J. Neurophysiol. 39: 282-300.

Zarbin, M. A., J. K. Wamsley, and M. J. Kuhar (1981) Glycine receptor: Light microscopic autoradiographic localization with $\left[{ }^{3} \mathrm{H}\right]$ strychnine. J. Neurosci. 1: 532-547. 